\title{
SEXUAL HEALTH
}

publish.csiro.au/sh

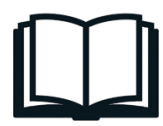

\section{SCOPE}

Sexual Health publishes original and significant contributions to the fields of sexual health including HIV/AIDS, sexually transmissible infections, issues of sexuality and relevant areas of reproductive health. This journal is directed towards those working in sexual health as clinicians, public health practitioners, or researchers in behavioural, clinical, laboratory, public health or social sciences.

The journal publishes peer reviewed original research, editorials, review articles, topical debates, case reports and critical correspondence. Authors interested in preparing a feature article, a mini-review or a viewpoint article are invited to discuss the matter with the Editor.

\section{AUTHOR BENEFITS}

- International reach and discoverability

- Indexing in a wide variety of relevant databases, including MEDLINE/PubMed

- Professional copyediting for every paper

- Capture impact through citation tracking and Altmetrics

- Authors retain copyright

- Green Open Access with no embargo

- Gold Open Access compliant with major funders

- No page charges

- Online publication ahead of issue release

- Eligible authors receive APC-free Open Access

\section{STAY IN CONTACT}

- publishing.sh@csiro.au

- Join the conversation on social media using hashtag \#SexualHealth

- Sign up for free journals content emails publish.csiro.au/earlyalert

- Recommend the journal to your librarian publish.csiro.au/journals/recommend

\section{SUBMIT YOUR ARTICLE ONLINE}

- Prepare: publish.csiro.au/sh/forauthors

- Submit: mc.manuscriptcentral.com/csiro-sh

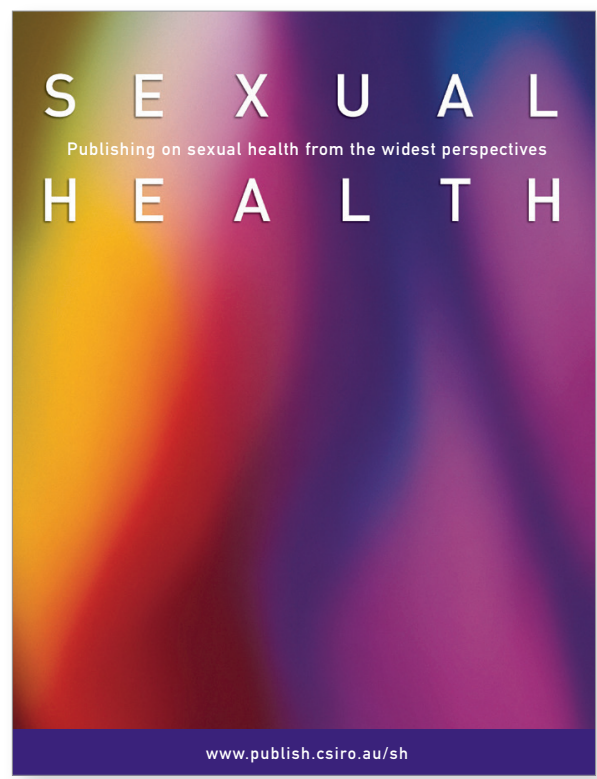

Editors-in-Chief:

Christopher Fairley

Monash University

Roy Chan

National Skin Centre, Singapore

Publishing Model: Hybrid

Open Access options available

Frequency: 6 issues/year

Publishing since: 2004

eISSN: $1449-8987$ (online)

Official journal of:

The International Union against Sexually Transmitted Infections (IUSTI), Asia-Pacific The Asia-Oceania Federation of Sexology

$$
\begin{array}{l|l|l|l}
\text { G } & \text { O } & \text { P } & \text { E }
\end{array}
$$$$
\text { JM12806 }
$$

As a member of the Committee on Publication Ethics (COPE), Sexual Health supports its core practices and is committed to transparency in scholarly publishing.

LEARN MORE ABOUT THE JOURNAL

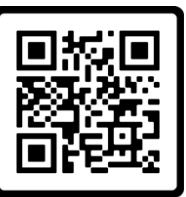

SCAN ME 


\section{JOURNAL METRICS}

\section{SPEED}

21 days from manuscript submission to first decision

68 days from manuscript acceptance to publication

\section{USAGE}

103,882 downloads in 2021

668 Altmetrics mentions in 2021

\section{REJECTION RATE}

$\mathbf{7 4 \%}$ rejection rate in 2021

\section{IMPACT}

Ranking in area

\# 166/210 in Public, Environmental and Occupational Health (Q4); 81/94 in Infectious Diseases (Q4)

\subsection{Impact Factor}

IF $\mathbf{2 . 3} 5$-Year Impact Factor

TC

JCI

1759 Total Citations in 2021

\subsection{Journal Citation Indicator}

\subsection{CiteScore}

Highest percentile 66\% (191/562 Public Health,

CS Environmental and Occupational Health)

\subsection{SNIP}

SNIP

Source Normalised Impact per Paper

\section{$0.9 \mathrm{SJR}$}

SJR

\section{8 h5-index}

h5 Google Scholar index for papers published 2017-21

\section{ABOUT CSIRO PUBLISHING}

CSIRO Publishing operates as an editorially independent science publisher within Australia's premier research group, Commonwealth Scientific and Industrial Research Organisation (CSIRO), and has been publishing journals since 1948. Our internationally recognised publishing program includes journals, books and magazines and covers a wide range of scientific disciplines.

\section{PARTNER ORGANISATIONS}

The Association of Society Publishers

Copyright Clearance Center
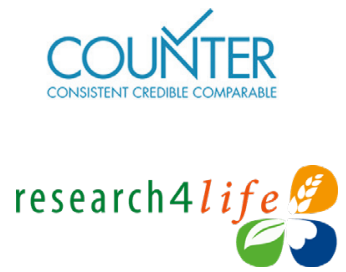

Crossref

Altmetric

$\$$ Dimensions

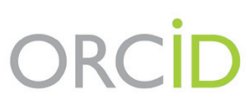

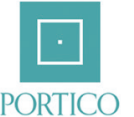

publons 